\title{
Towards a Modeling approach based on Software Components
}

\author{
Fadoua Rehioui \\ Laboratory of Modeling and Computation, \\ University Sultan Moulay Slimane \\ B.P. 523, Faculty of Sciences and Technology \\ Beni Mellal, Morocco
}

\author{
Abdellatif Hair \\ Laboratory of Modeling and Computation, \\ University Sultan Moulay Slimane \\ B.P. 523, Faculty of Sciences and Technology \\ Beni Mellal, Morocco
}

\begin{abstract}
Software industry is moving towards a component-based development but more research is still needed for reliable and efficient software components.

The objective of this work is to propose an approach to developing software components of the system from use cases. This approach consists of four stages and is based on the decomposition of use cases into elementary actions and the factorization of the past for system software components.
\end{abstract}

\section{General Terms}

Engineering based software components; Software Components Approach

\section{Keywords}

Software components, factorization data, use cases, subcomponent, actions, approach.

\section{INTRODUCTION}

The evolution of software engineering has resulted in a significant interest in the development of software. This interest is motivated by the reduction of development time of applications, the requirement of excellent quality, to constantly adapt to changes and be easily used in other applications. Therefore, strategy development software modules must be defined in advance in terms of clarity, performance, and ease of integration. This type of software module is called software component, which is an element or unit of software, implemented as a piece in applications. The term component is used in several research fields, such as computer-aided design, software engineering, artificial intelligence, information systems and databases.

The idea of the component was firstly proposed in 1968 by Douglas McIlroy [6], [12]. This new era of componentoriented started to grow 30 years later: Sun "EJB" [20], OMG [15], "CCM" [3], Microsoft ". NET / COM" [13], etc...

The software industry is moving towards a componentbased development, and research is still needed for reliable and efficient software components. In fact, there is no standard for modeling a component-based system. Therefore, it is necessary to try to propose an approach based on use case to illustrate the functional behavior of a software system and to identify its components.

Components modeling starting from use cases envisages the precision of development and identification of specific components. Use cases are, by their nature, models that ensure the consistency of development process components and the connection to the system architecture.
This article aims to present our contribution, which is to combine a new development of software components from use cases.

This document is structured as follows:

The following section is devoted to the state of the art of engineering based software components approaches. Section 3 is devoted to the presentation of the proposed approach and its different views. Section 4 formalizes the steps of the proposed approach and its implementation on Account Management as a case study. Section 5 presents a conclusion and perspectives.

\section{ENGINEERING COMPONENT- \\ BASED}

The field of engineering methods deals with the definition of new engineering modeling methods, conception and adaptation of techniques and tools for the development of information systems [20].

For good quality software improvement, several analysis and design methods have been developed such as Merise [19], which was used in 1980 for project management organizations, and currently limited to a specific area, especially its inefficiency in the modeling of software components. Later, several object-oriented analysis and conception methods have been developed, namely Rumbaugh OMT [21] BOOCH [1] and OOSE Jacobson [8]. In 1994, Rumbaugh, Booch and Jacobson decided to unite in the development of a new method called UP (Unified Process) [9] which defines a generic framework for developing object with UML (Unified modeling language) [22] as a modeling language, and which is centered on the architecture and guided by use cases .

Despite the strength of these methods, they do not exploit the principle of consistency of conceptual modeling object until the obtaining of system code. To fill this lack, methods based components intend to improve the cost and development time by code fragments and assemble them to form a new application. Among these methods it can cite:

Catalysis is a method of design systems based on components originally developed by Desmond D'Souza and Alan Cameron Wills in 1998 [4]. Catalysis improves and extends UML by extensions in order to represent the logical level of components that the physical level of component on UML. The components of the Catalysis method are abstract, and defined as a 'Type', each 'Type' is a stereotyped class. One type has a behavior in a domain, which the external behavior of each 'Type' is defined by its interfaces.

J. Cheesman and J. Daniels proposed the method UML Component [2] . This method is inspired by several methods, such as Catalysis and RUP [10]. The method focuses on the specification of components by enriching the UML notation with stereotypes, in order to describe the specification of components. The identification of the components is made 
from trade concepts, described and grouped by the notion of "types". The proposed method is limited to the conception level. Indeed, it does not explain how to interpret the specification of the component in the implementation, or how to check the specifications at the compilation level.

Proposed by Emmanuel Renaux [18] CUP method is an adaptation of the Unified Process (UP) oriented to systems based on components. The method aims to provide a structured approach to develop software based components. It uses more the UML notation to express the concept of components during the life cycle of software development and not to the deployment phase and provides early the identification of components (logical components).

The VUML (View based Unified Modeling Language) method is an extension of UML but oriented viewpoint developed by Mahmoud Nassar [14]. It is based on the principle that a software system is a combination of objects, views and perspectives. The main addition to the UML is the concept of multiviews class that combines the concept of flexibility via the notion of viewpoint. This multiview class is composed of a base entity (part shared by all actors) having entities-view (extensions of the base entity). Multiview component concept was introduced in VUML in component diagrams so that entities-view becomes internal subcomponents of the base component from the base entity (multiview class) [14].

The construction of a method should be based on the principle of agreement of this method with the various projects. That is to say, the engineering of methods in its turn poses a problem in the construction of a flexible approach and easily adapted to the situation of each project [20].

Most of these proposed methods based on the software components except the CUP, do not have neither early and clear identification of components from use cases, nor good identification and consistency of internal and external elements of the component for the rest of development cycle of the system, which makes these methods non-stringent and inappropriate methods.

\section{PROPOSED COMPONENT-BASED APPROACH}

A software architecture which is undertaken and directed by the use cases during development would require work from different views.

The system architecture based on the use of views identifies the description of the design addressing different issues. This description consists of four views: the use case view allows to formalize the user requirements and their interpretations in the system specification.

The component design view allows the visualization of the organization of the components in the development environment. The interface view describes the set of interfaces of achieved components.

And the components assembly view stands for the system in the environment of its components and their interactions.

The proposed approach is described by these four system views, each of which includes a set of steps developed in order to meet all the needs of system users. Each of these views describes dependencies with other views and ensures overall consistency and a direct correspondence of the system during the execution of the process.

\subsection{View of the use case}

All the specifications of an information system are described in view of the use case. Having fully described the use cases, the use case view represents the needs of the system in the form of components, bringing together all the use cases with the actor concerned for the use case view, which identifies from the outset all product components.

Then, use cases are decomposed into a set of actions from the scenarios of the system, and then the actions discoveries are factored to parts which will be then sub-components. Part is defined informally as a "concept data" corresponding to a list of actions of use case or to a result of an interaction of group actions of use cases. This leads to develop a number of actions (elementary activities of a user) [7] integrated into a table decomposition of use cases.

\subsection{View component design}

A component is a self-contained module having an internal structure and a set of ports that structure the points of interaction with the external environment with a set of interfaces provided and / or required [24].

The view component design describes the structure of the elements of architecture of component and its relationships. It represents the internal structure of the component, and its subcomponents. The model component design is the element of the architecture that will be deployed and executed (see Figure 1)

\subsection{Components provided/required interfaces View}

An interface is a relationship of dependency "use / provide" between the component and its environment, but the behavior of the services offered via this interface will change according to the use case in question. These interfaces are characterized by the signatures of the methods they define and make sense of communication (provided; incoming / required; outgoing). The interface view represents the component specification, through its ports required / provided which express the interaction between components.

The method given in the interface identification is to use the suitable and the various actions identified above for use case view concerned.

\subsection{Assembly view}

The assembly view shows the overall system by giving a representation [17] of software components and their interactions. The interaction between components via a port is made through connectors that connect component ports [5]. Indeed, a component must first activate, dynamically, a subcomponent before interacting with another component via a corresponding connector.

A connector connects two or more connectable elements (port, component). Each end of the connector plays a different role in the communication between connectable elements. It can be delegated or assembly. A delegation connector connects a component to its internal sub-components [5].

An assembly connector connects two elements (component or port), one requesting services provided by the other.

A connector assembly is all the hardware and software to specify and implement the interaction between components. 


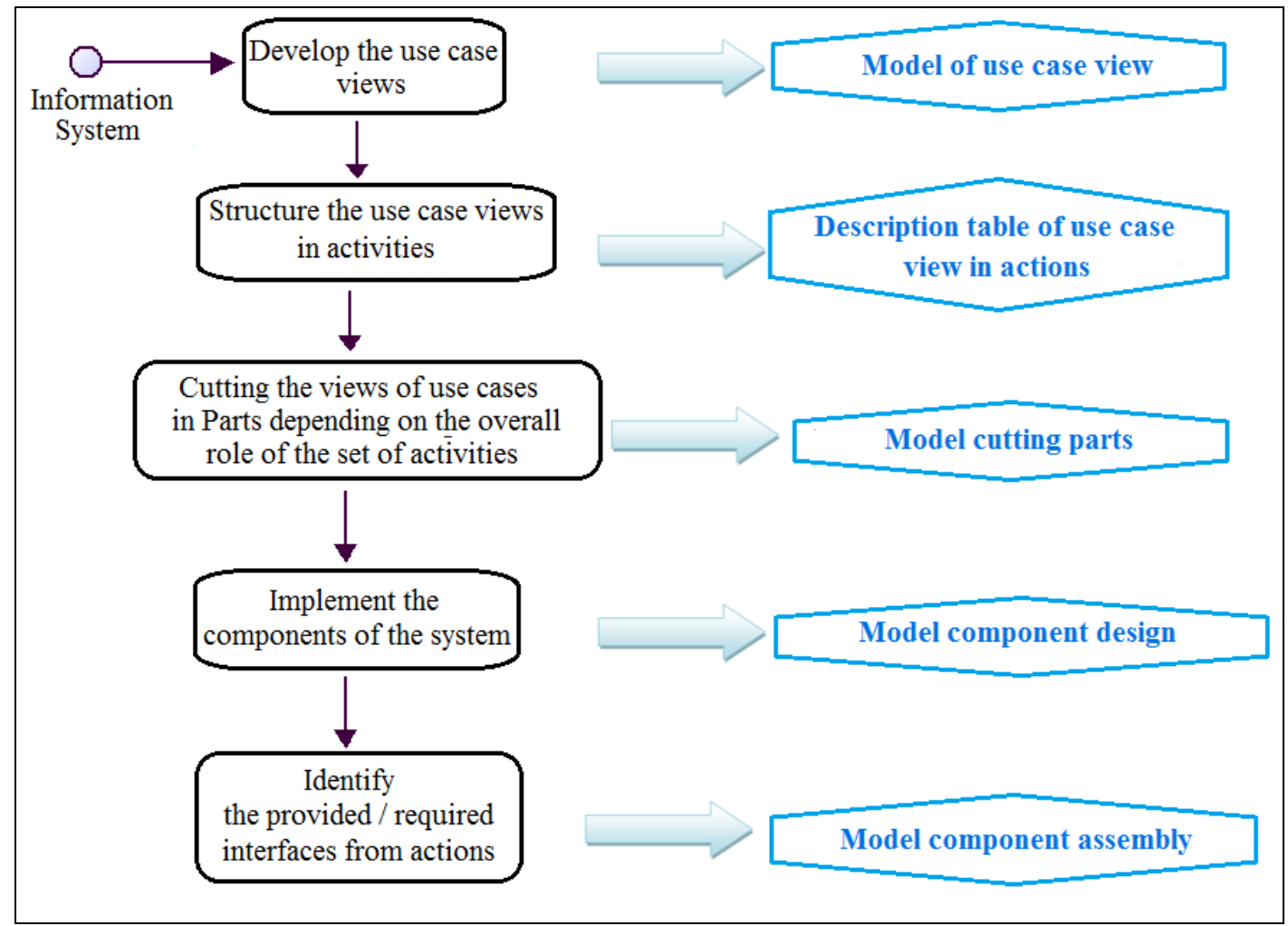

Fig 1: Seen of the proposed approach

\section{PRESENTATION AND CASE STUDY}

The purpose of this work is to propose a new method which allows to describe the needs of users of the system, using use cases to elaborate system software components. The proposed method models a system according to its different users (actors). The presentation of the method is illustrated by the case study of an ATM of a bank that allows withdrawing money (take out), depositing money and checking the balance of a customer. A main scenario is presented below to show an example of system operations.

1. The customer identifies himself by inserting a bank card into the distributor

2. The distributor checks the validity of the card

3. The customer enters his PIN

4. The distributor checks the code

5. The customer chooses the operation "Cash withdrawal"

6 . The customer specifies the amount to withdraw

7. The distributor checks and request the computer system to

debit the account

8 . The customer takes money

9. The distributor asks the customer to continue or not

10. The customer chooses the operation " Cash deposit "

11. The customer deposits money

12. The distributor account money

13. The distributor request confirmation of the amount

14. The customer confirms the amount deposited

15. The distributor delivers a deposit slip (receipt)

16. The customer takes the deposit slip

17. The customer withdraws his card

\section{Alternative: incorrect PIN}

In step 4 of the main scenario, the PIN is incorrect.

The distributor asks again the secret PIN

The customer enters his PIN

The distributor checks the PIN

Precondition

The customer must have a credit card

Post- condition for success

The customer has the card and Cash money

\subsection{Identification of constituents}

This step consists of identifying the various components of the case treated by identifying the needs of the system. This identification of needs includes identification of actors (participants) use cases of the system. An "actor" is typically a person or may even be another computer system, as is the case with "ATM".

The use case diagram is developed to express the interactions between the system and the actors of the system.

Two main actors in our system are identified (see Figure 2):

- The actor Customer-Bank identifies for "Withdraw Money

", for "Deposit Money" or / and for "View the Balance."

- The actor Cash-register that supports the operations performed by the customer.

The identification of components is realized as a cluster of partial use cases of a set of scenarios in use cases view. This grouping of use cases is based on the decomposition of use cases in actions of an actor. This allows early identification of all software components of our system from use cases. 


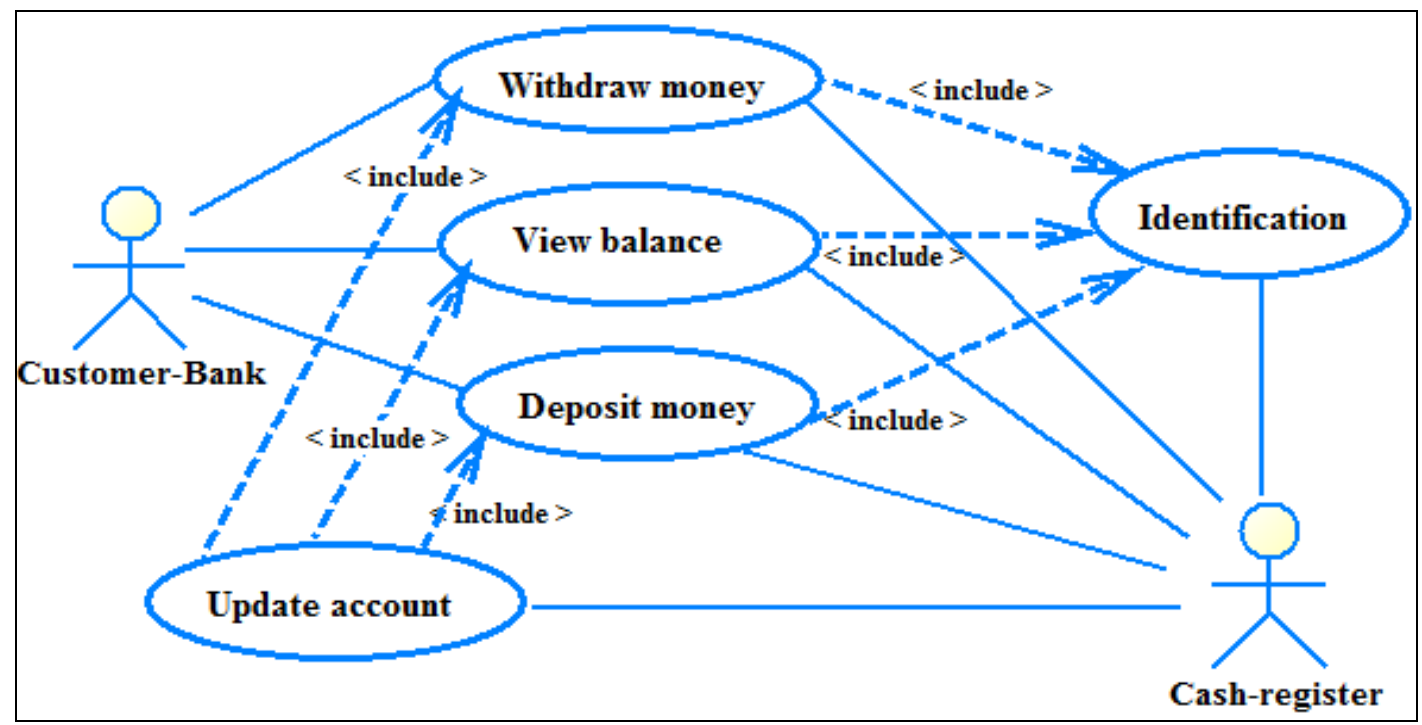

Fig 2: Diagram Use Case

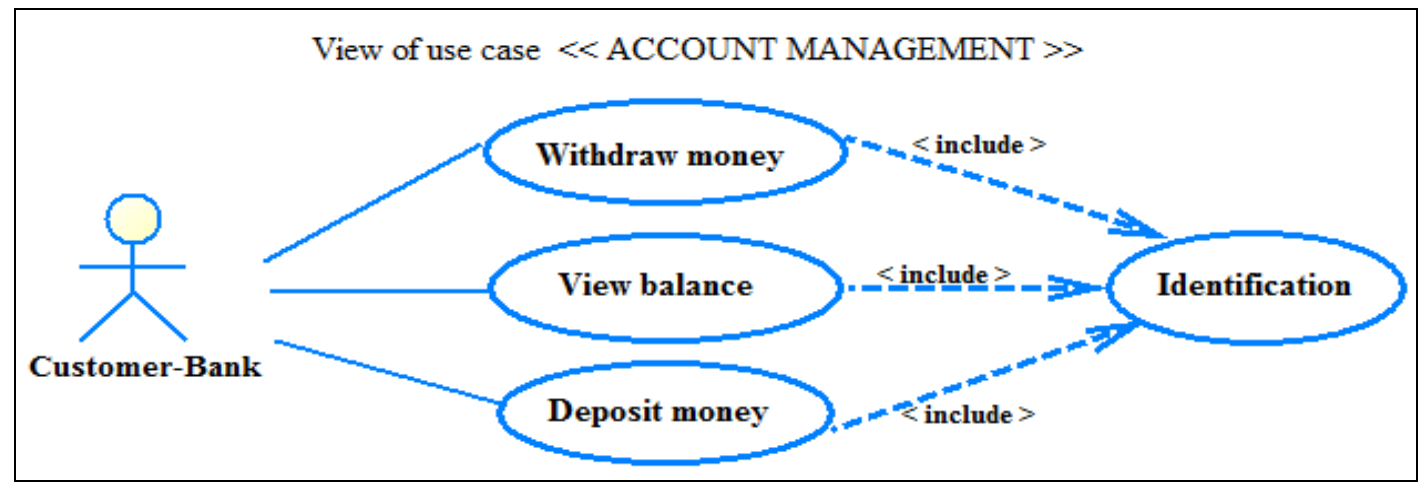

Fig 3: View of use case "ACCOUNT MANAGEMENT" of the CUSTOMER actor

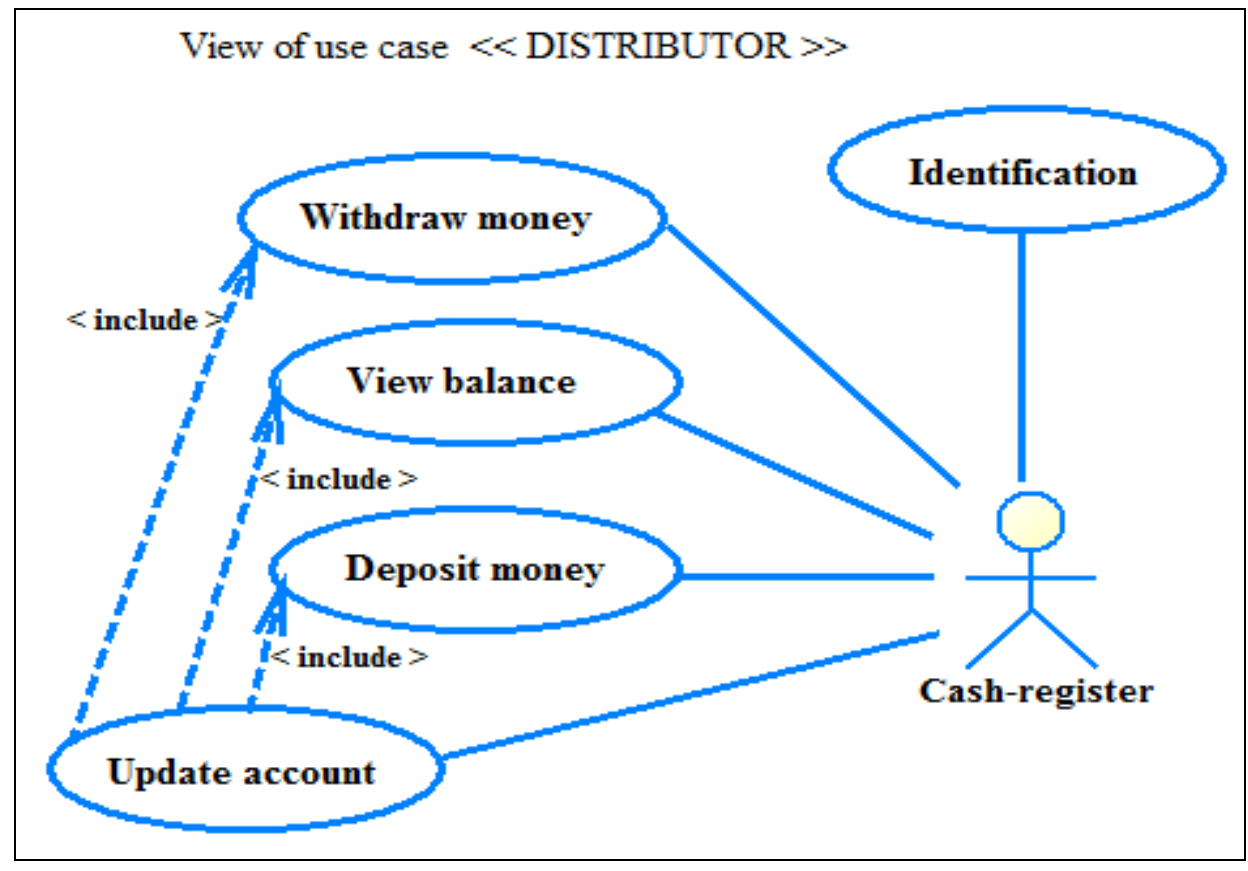

Fig 4: Use Case View "DISTRIBUTOR" actor CASH-REGISTER 


\subsection{Elaboration of actions}

This step consists of cutting and designing use cases in various elementary actions of actors in the system (Table 1) where action is an effect produced by an actor to achieve an objective. Here, the inclusion relation ("includes", Figure 2) expresses the fact that a use case includes a consecutive sequence of actions and it is possible to factor (i.e. find what is common in actions and group ) with other cases of use.

Table 1. Description of use case views of the system BANK

\begin{tabular}{|c|c|c|}
\hline Actor & Use Case & Decomposition action \\
\hline \multirow{3}{*}{$\begin{array}{c}\text { Customer- } \\
\text { Bank }\end{array}$} & $\begin{array}{c}\text { Withdraw } \\
\text { money }\end{array}$ & $\begin{array}{l}\text { a1: customer identifies itself } \\
\text { by his card } \\
\text { a2: customer enters his PIN } \\
\text { a3: customer chooses "Cash } \\
\text { withdrawal" operation } \\
\text { a4: customer specifies the } \\
\text { amount to withdraw } \\
\text { a5: customer takes money } \\
\text { a6: customer takes the card }\end{array}$ \\
\hline & $\begin{array}{c}\text { View } \\
\text { (Ckeck) } \\
\text { balance }\end{array}$ & $\begin{array}{l}\text { a1: customer identifies itself } \\
\text { by his card } \\
\text { a2: customer enters his PIN } \\
\text { a7: customer chooses } \\
\text { operation "View balance" } \\
\text { a6: customer takes the card }\end{array}$ \\
\hline & $\begin{array}{l}\text { Deposit } \\
\text { money }\end{array}$ & $\begin{array}{l}\text { a1: customer identifies itself } \\
\text { by his card } \\
\text { a2: customer enters his PIN } \\
\text { a8: customer chooses the } \\
\text { operation "Cash deposit" } \\
\text { a9: customer deposits money } \\
\text { a10: customer validate or not } \\
\text { the amount deposited } \\
\text { a11: customer takes the } \\
\text { deposit slip } \\
\text { a6: customer takes the card }\end{array}$ \\
\hline & $\begin{array}{c}\text { Withdraw } \\
\text { money }\end{array}$ & $\begin{array}{l}\text { a12: the Cash-register checks } \\
\text { the validity of the card } \\
\text { a13: the Cash-register checks } \\
\text { the code } \\
\text { a14: the Cash-register checks } \\
\text { the balance } \\
\text { a15: the Cash-register debit } \\
\text { the account by the amount } \\
\text { requested }\end{array}$ \\
\hline $\begin{array}{l}\text { Cash- } \\
\text { register }\end{array}$ & $\begin{array}{l}\text { View } \\
\text { balance }\end{array}$ & $\begin{array}{l}\text { a12: the Cash-register checks } \\
\text { the validity of the card } \\
\text { a13: the Cash-register checks } \\
\text { the code } \\
\text { a14: the Cash-register control } \\
\text { the balance } \\
\text { a16: the Cash-register displays } \\
\text { information }\end{array}$ \\
\hline
\end{tabular}

\begin{tabular}{|c|c|c|}
\hline \multirow[t]{3}{*}{$\begin{array}{l}\text { Cash- } \\
\text { register }\end{array}$} & $\begin{array}{l}\text { Deposit } \\
\text { money }\end{array}$ & $\begin{array}{l}\text { a12: the Cash-register checks } \\
\text { the validity of the card } \\
\text { a13: the Cash-register checks } \\
\text { the code } \\
\text { a17: the Cash-register counts } \\
\text { the money } \\
\text { a18: the Cash-register request } \\
\text { confirmation of the amount } \\
\text { a19: the Cash-register issue a } \\
\text { deposit slip (receipt) of the } \\
\text { amount paid }\end{array}$ \\
\hline & $\begin{array}{c}\text { Identification } \\
\text { Customers }\end{array}$ & $\begin{array}{l}\text { a1: customer identifies card } \\
\text { a12: the Cash-register checks } \\
\text { the validity of the card } \\
\text { a2: customer enters his PIN } \\
\text { a13: the Cash-register checks } \\
\text { the code }\end{array}$ \\
\hline & Update & $\begin{array}{l}\text { a20: Save operations } \\
\text { a21: Update Account }\end{array}$ \\
\hline
\end{tabular}

After decomposing use cases in a series of actions, the actions found are factored in parts which will be then sub-components [11].

This factorization of actions use cases concerning CUSTOMER-BANK and the CASH-REGISTER actors of system leads to constitute parts from a list of actions (a1 to a20). The parts produced are:

The customer is the operator, ie d. operations are performed by the customer.

P1: WITHDRAWAL $\rightarrow$ a3, a4, a5

P2: DEPOSIT $\rightarrow$ a8, a9, a10, a11

P3: BALANCE INQUIRY $\rightarrow$ a7

The operator is the cash-register; it supports the execution of operations.

P4: IDENTIFICATION $\rightarrow$ a1, a12, a2, a13

P5: WITHDRAWAL $\rightarrow$ a14, a15

P6: DEPOSIT $\rightarrow$ a17; a18; a19

P7: BALANCE INQUIRY $\rightarrow$ a14, a16

And P8: UPDATE $\rightarrow$ a20; a21

According to this decomposition, it see that P1, P2 and P3 refer to shared parts P5, P6 and P7 whose functionality depends on the actor of the system.

Relationship "include" is a relationship in which a use case (base use case) includes another use case features (inclusion use case). It supports the reuse of functionality in a use case.

In Figure 2, "Withdraw money", "View Balance" and "Deposit money" of CUSTOMER-BANK, are base use cases of inclusion use case "Identification" of CASH-REGISTER, according to the "includes" relationship.

"Update Account" of actor CASH-REGISTER is a base use case with respect to inclusion use cases "Withdraw Money", "View Balance" and " Deposit Money" of the CUSTOMERBANK actor.

And thereafter, the actions corresponding to base use cases are a1, a2, a3, a4, a5, a6, a7, a8, a9, a10, a11, a20, and a21. Similarly, the actions corresponding to the inclusion use case are a12, a13, a14, a15, a16, a17, a18, and a19.

Therefore, these actions of base use cases represent a source of information in relation to other actions in the inclusion use case. 
Therefore, the parties WITHDRAWAL, CONSULTATION and DEPOSIT of the view use case ACCOUNT are sources of information to the view use case DISTRIBUTOR.
The approach is to associate with each actor (i.e. a use case view) a part or group of parts that meets the needs of the actor (see Figure 5).

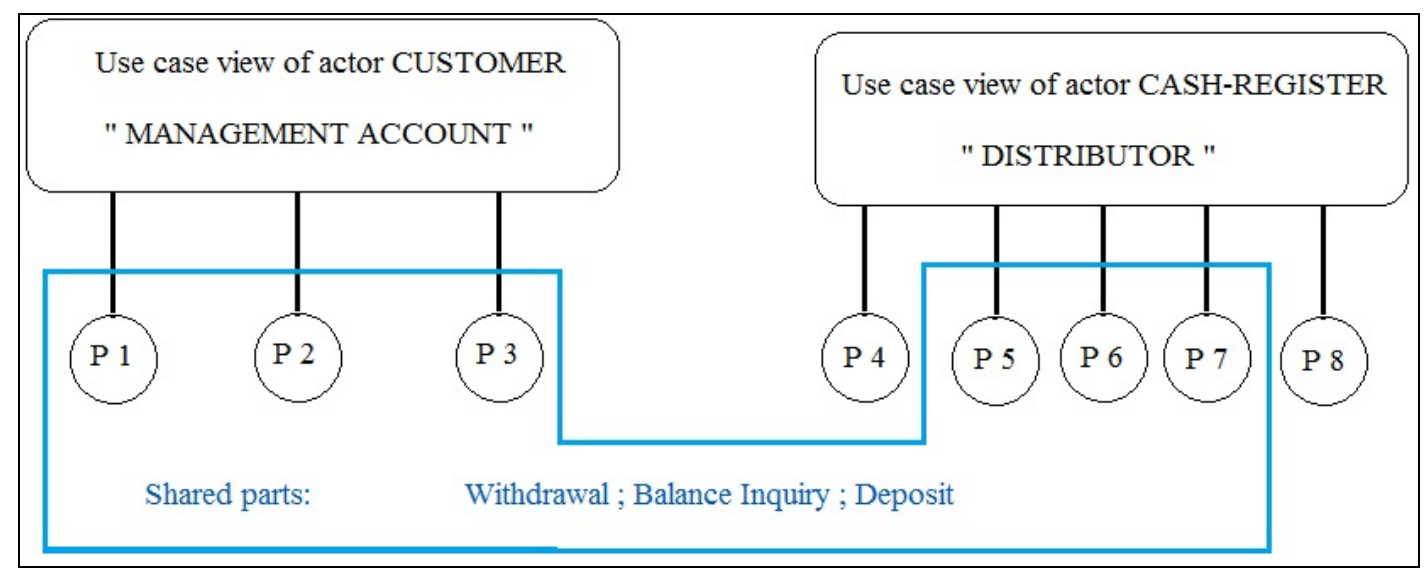

Figure 5: Cutting of use case view in parts

\subsection{Identification components}

This is a step that aims to associate combinations of parts obtained at the end of the previous step in order to develop the various components and sub-components of the system.

Generation model of component design view is carried from the stage "Elaboration of activities " of the components of the system, so that the parts (WITHDRAWAL, BALANCE INQUIRY, DEPOSIT, IDENTIFICATION, AND
REGISTRATION/UPDATE ) become sub-components of DISTRIBUTOR component and parts (WITHDRAWAL, BALANCE INQUIRY, DEPOSIT) become subcomponents of ACCOUNT component (see Figure 6).

The communication between the sub-components is via ports input / output interconnected to ensure the proper functioning of the system.

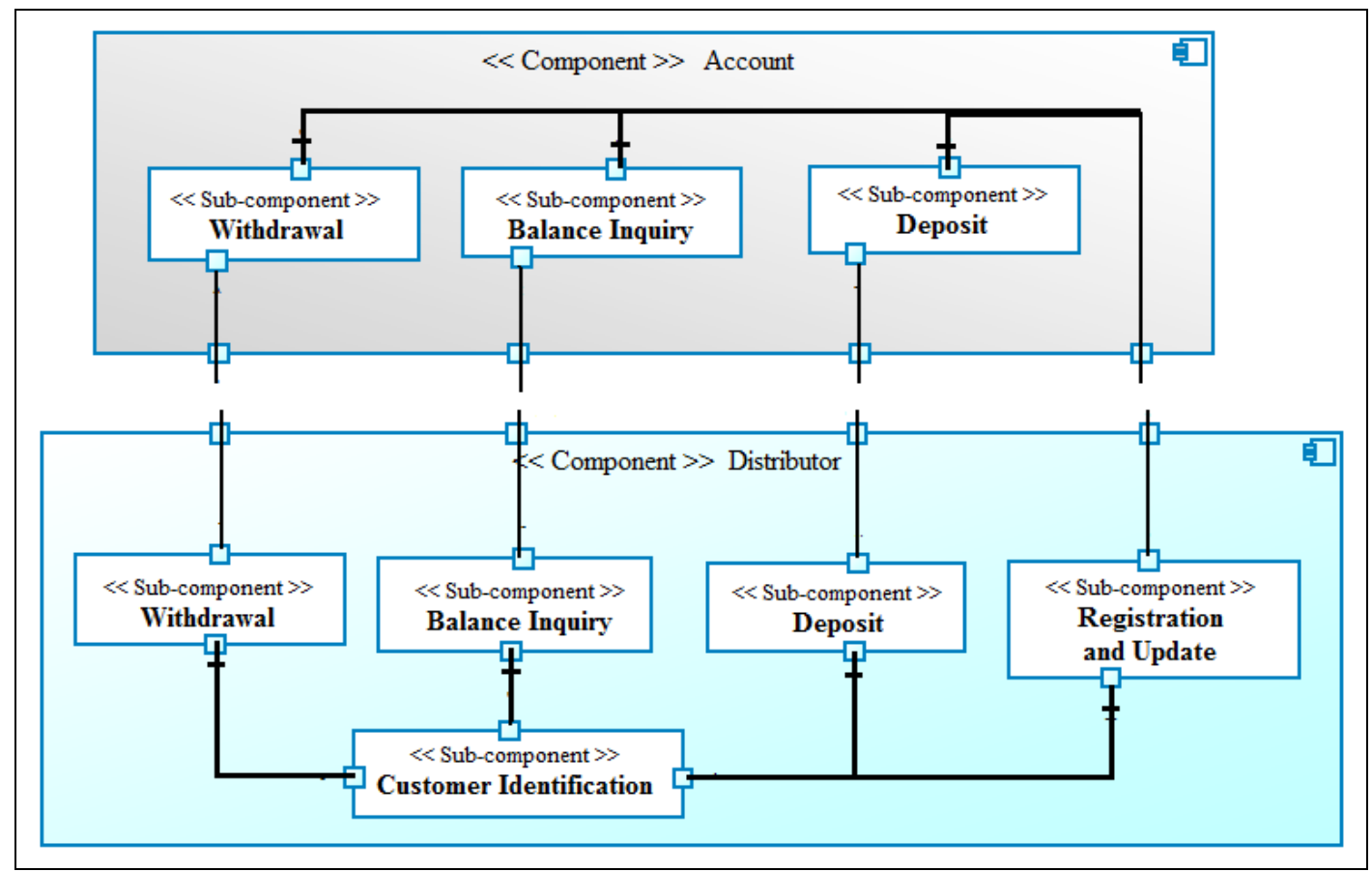

Figure 6: Diagram of component of use case view CASH-REGISTER

Identification of interfaces provided / required is based on the actions defined in the step of identifying the components (Table 1), so it is necessary to know first the sub-components, which are sources of information and have strong values. To identify the interfaces provided / required, the procedure is as follows:
Firstly, it must know the source sub-components of information and strong values that will provide the interfaces provided.

According to the previous phase, it was found that the parts WITHDRAWAL, CONSULTATION and DEPOSIT of the view use case ACCOUNT, are sources of information to the view use case DISTRIBUTOR. Therefore, these parts become sub-components and provide interfaces provided. 


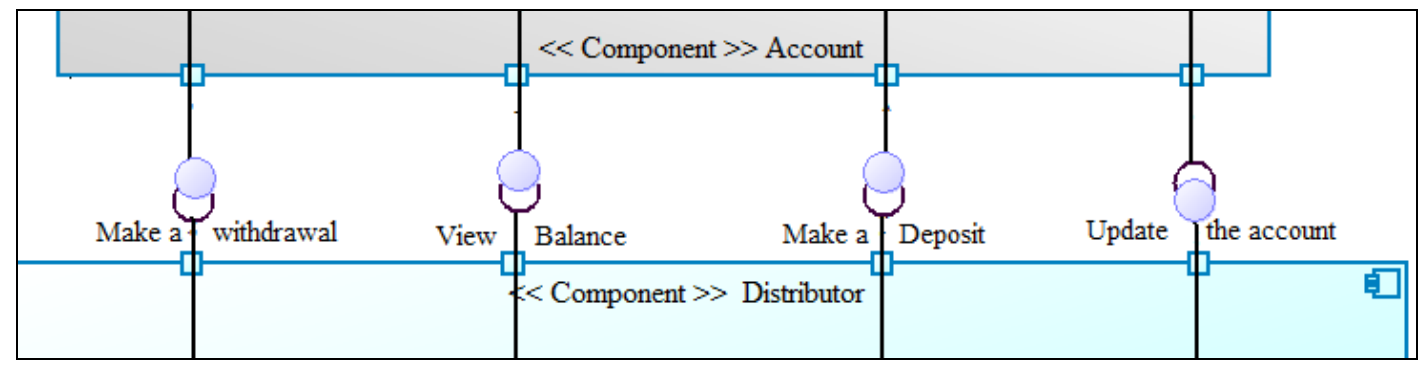

Figure 7: Diagram of component of use case view CASH-REGISTER

As for the "REGISTRATION AND UPDATE" part of the view use case DISTRIBUTOR, it becomes a sub-component to having a provided interface for the sub-components of ACCOUNT component.

The sub-component WITHDRAWAL of ACCOUNT component provides an interface provided called "Make a Withdrawal" derived from actions a3 and a14 describing more the role of the interface to WITHDRAWAL sub-component of DISTRIBUTOR component.

For BALANCE INQUIRY sub-components of ACCOUNT component, it offers a provided interface called "View Balance" from action a7 and a15 to BALANCE INQUIRY sub-component of DISTRIBUTOR component. The REGISTRATION AND UPDATE sub-component of DISTRIBUTOR component offers provided interface to the three sub- component of ACCOUNT component as name "Update Account" from actions a19 and a20.

In summary, the "View Balance", "Make a Deposit" and "Make a Withdrawal" are interfaces provided of the ACCOUNT component towards the DISTRIBOTOR component and are interfaces required of the DISTRIBOTOR component towards the ACCOUNT component. As for the interface "Update the account", it is a required interface of the ACCOUNT component towards the DISTRIBUTOR component and is a provided interface of the DISTRIBUTOR component towards the ACCOUNT component.

In Figure 7, it represents the interfaces provided by a gray disk, and required interfaces are symbolized by a black half circle.

\subsection{Assembly components}

In the assembly of system components, the ACCOUNT component interacts with the DISTRIBUTOR component, hence the assembly of system components through ports (Figure 8). Figure 8 shows the simplified diagram of components. This diagram shows two components (DISTRIBUTOR and ACCOUNT) that interact with each other via ports and shows assembly connectors and delegation connectors for ACCOUNT component. It can differentiate a delegation connector connecting the three sub-components WITHDRAWAL, BALANCE INQUIRY and DEPOSIT with the sub-component CUSTOMER IDENTIFICATION. For the assembly connectors, there are four connectors connecting the DISTRIBUTOR component with the ACCOUNT component.

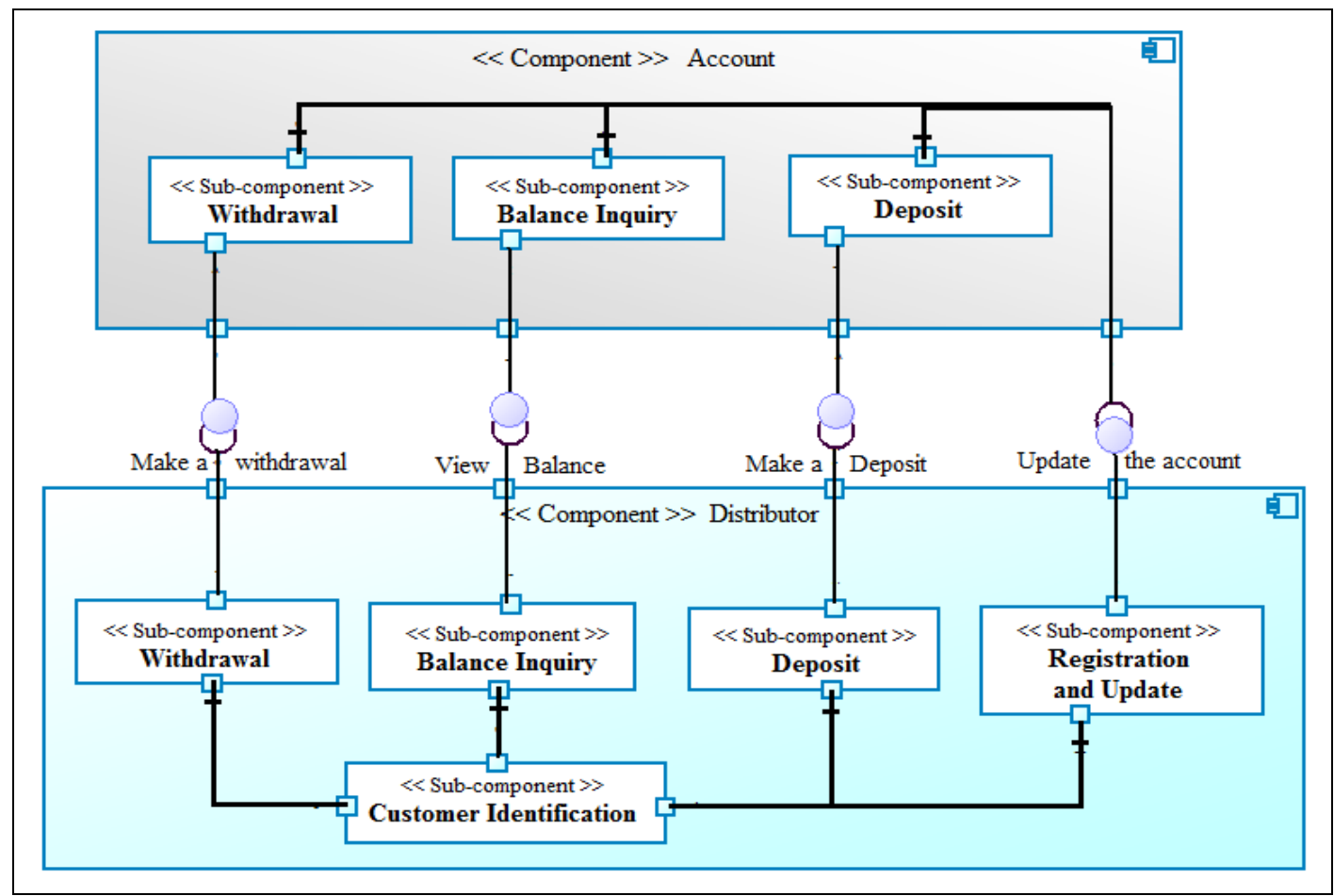

Fig 8: Assembly components view (ACCOUNT, DISTRIBUTOR) 


\section{CONCLUSION AND PERSPECTIVES}

The software components are interested in problems that are not taken into account until now. They have a particular vision of how to develop softwares; they are processes that provide steps to drive the development.

It is no coincidence that the notion of component provides great interest for the development of complex systems. It presented an engineering approach based on components that is based on the factorization data process with its four stages: identification of the constituents, development activities of the constituents, identification of system components and component assembly.

The use of actions has shown its effectiveness for the identification of sub-components and interfaces in all steps of the proposed approach.

Currently, the research focuses on the complete definition of approach conception of information systems based on components. This type of research should lead to a real and effective method of engineering domain. The objective is to define a method of analysis/conception of components in modeling complex systems.

\section{REFERENCES}

[1] Booch.G. 1993. Object-oriented Analysis and Design with Applications (2nd ed. ed.). Redwood City: Benjamin Cummings. ISBN 0-8053-5340-2.

[2] Cheesman.J. and Daniels.J. 2001. UML Components - A Simple process for specifying Compnent-Based software , Addison-wesley.

[3] CORBA. 2014. http://www.omg.org/spec/CORBA/3.3/

[4] D'Souza.D.F. and Wills.A.C. 1998. Objects, Components, and Frameworks with UML - The Catalysis Approach. ADDISON-WESLEY.

[5] B.E. El Asri, M. Nassar, B. Coulette, and A. Kriouile. 2006. "Architecture d'assemblage dynamique de composants multivues dans VUML", ;in Proc. INFORSID, 2006, pp.943-958.

[6] Fabresse.L. 2007. Du découplage à l'assemblage nonanticipé de composants Conception et mise en oeuvre du langage à composants SCL.

[7] Hair. A, Krioule.A, Coulette.B, 2002. Un processus d'analyse et de conception unifié basé sur le concept de point de vue. Actes de CARI'02, Octobre, Yaoundé, Cameroun.

[8] Jacobson.I. 1992. Object-Oriented Software Engineering: A Use Case Driven Approach. ISBN 0-201-54435-0.

[9] Jacobson.I. Booch.G. and Rumbaugh;J. 1999. The Unified Software Developement Process, AddisionWesley.

[10] Kruchten P. 1998. The Rational Unified Process: An Introduction.

[11] Kriouile. A. 1995. VBOOM, une méthode orientée objet d'analyse et de conception par points de vue. Université Mohammed V de Rabat.

[12] McIlroy.M.D. 1968. Mass produced software components. In Proceedings, NATO Conference on Software Engineering, éditeurs P. Naur et B. Randell, Garmisch, Germany. [McIlroy, 1968, http://fr.wikipedia.org/wiki/Douglas_McIlroy

[13] Microsoft. 2014. NET Framework Developer Center, http://msdn.microsoft.com/fr-fr/vstudio/aa496123.

[14] Nassar.M. 2005. Analyse/conception par points de vue: le profil VUML. Thèse en Informatique à L'institut National Polytechnique De Toulouse.

[15] OMG. 2014. O.M.G. Home Page, http://www.omg.org,

[16] Renaux.E. 2004. Définition d'une démarche de conception de système a base de composants, Université de Lille 1.

[17] Renaux.E. 2004. Les composants logiques : vers une ingénierie à base de composants. 59655 VILLENEUVE D'ASCQ cedex.

[18] Renaux .E, CARON.O and GEIB.J.M. 2003. The Component Unified Process Project. In SEA'03, page 669-647, Los Anglos USA,.IASTED,ACTA Press.

[19] Rochfeld.A. et Colletti.R. 1983. La Méthode Merise Tome 1 : Principes et outils. Éditions d'Organisation, Paris.

[20] Sun. (2014). E.J.B. HomePage, http :www.oracle.com/technetwork/java/javaee/ejb/index .html, 